Revista Española de Antropología Americana ISSN: 0556-6533

https://doi.org/10.5209/reaa.64963

\title{
Leyendo la historia de Ek' Balam: breve relato del trabajo del Dr. Alfonso Lacadena García-Gallo
}

\author{
Leticia Vargas de la Peña y Víctor R. Castillo Borges ${ }^{1}$
}

Recibido: 14 de noviembre de 2018 / Aceptado: 9 de febrero de 2019

Resumen. Este trabajo no pretende presentar nuevos datos sobre Ek' Balam, sino hacer un breve recuento del trabajo realizado por el Dr. Alfonso Lacadena García-Gallo con los textos jeroglíficos del sitio. Es un pequeño tributo a su valiosa contribución al conocimiento de Ek' Balam y su historia dinástica. Sin sus conocimientos y su compromiso con el trabajo, no tendríamos hoy la valiosa información que nos legaron los antiguos habitantes del reino de Talol.

Palabras clave: epigrafía maya; textos glíficos; glifo emblema.

\section{[en] Reading the History of Ek 'Balam: A Brief Account of the Work of Dr. Alfonso Lacadena García-Gallo}

\begin{abstract}
This work is not intended to present new data on Ek' Balam, but to do a brief account of the work done by Dr. Alfonso Lacadena García-Gallo with this site's hieroglyphic texts. It is as a small tribute to his valuable contribution to the knowledge of Ek' Balam and its dynastic history. Without his knowledge and his commitment to work, we would not have today the valuable information that the ancient inhabitants of the realm of Talol inherited to us.
\end{abstract}

Keywords: Maya epigraphy; glyphic texts; emblem glyph.

Sumario. 1. El relato. 2. Referencias.

Cómo citar: Vargas de la Peña, Leticia y Víctor Castillo Borges. «Leyendo la historia de Ek’ Balam. Breve relato del trabajo del Dr. Alfonso Lacadena García-Gallo». Revista Española de Antropología Americana 49 (número especial): 121-138.

\section{El relato}

Ek’ Balam es un verdadero tesoro para cualquier investigador. Hemos dedicado veinticuatro años a su estudio, diecinueve de ellos junto con el Dr. Alfonso Lacadena García-Gallo, dentro del Proyecto de investigación y conservación arquitectónica en Ek'Balam, del Instituto Nacional de Antropología e Historia, en Yucatán, México.

Más de dos décadas de trabajo continuo con grandes satisfacciones, con un gran cúmulo de conocimientos y un sinnúmero de sorprendentes descubrimientos, incrementados con el hallazgo de textos jeroglíficos labrados y pintados en variadas

\footnotetext{
1 Arqueólogos del Centro INAH Yucatán. lvargas.yuc@inah.gob.mx, muyjoochak@gmail.com.
} 
superficies de los edificios de Ek' Balam y principalmente en su palacio real, que hemos llamado la Acrópolis. Todo este material obtenido es el que dio origen a una fructífera colaboración con el Dr. Alfonso Lacadena García-Gallo y también a una magnífica amistad.

Quien conociera a Alfonso podía notar la gran pasión que tenía por la epigrafía, así como la especial habilidad en su trabajo; todos sabemos también cómo lo disfrutaba y contagiaba su placer por el descubrimiento. Compartimos los tres un gran amor por Ek' Balam y nada nos hacía más felices que escuchar el entusiasmo y la efusividad con que nos comunicaba sus descubrimientos y nos traducía los maravillosos textos glíficos de Ek' Balam. Todavía recordamos nuestro corazón latiendo y la piel erizada de emoción al escuchar los poéticos textos.

Como comentamos en un artículo reciente, escrito en homenaje al Dr. Lacadena (Vargas y Castillo 2018), la verdad es que sentimos cierta desconfianza al pensar en él como colaborador, cuando lo conocimos en 1998 en el Museo Palacio Cantón de Mérida, pues no habíamos oído nada de acerca de él y pensamos que era muy joven para tener la experiencia necesaria. No sabíamos entonces que estábamos frente a una de las mentes más brillantes de la epigrafía maya y de la investigación histórica y lingüística en general, pero quizá una leve corazonada y mucha buena suerte, nos hizo creer en él y entregarle el material epigráfico hallado hasta entonces en Ek' Balam. Pronto comprendimos que habíamos tomado la mejor decisión, constatamos sus amplios conocimientos y también su compromiso y dedicación con el trabajo.

Desde 1997 habíamos iniciado las exploraciones en el edificio más grande e importante de Ek' Balam, el que después llegaríamos a identificar como el palacio real, que fue la creación y residencia de Ukit Kan Lek Tok', el iniciador de la dinastía reinante en Talol durante el Clásico Tardío (770-896 d.C.) y también de algunos de sus descendientes.

Los trabajos arqueológicos, principalmente los realizados entre 1998 y 2000 fueron muy intensos y nos condujeron a hacer continuos descubrimientos, entre los que había diversos materiales conteniendo textos jeroglíficos, pero esto se debía precisamente a que estábamos excavando el edificio principal del sitio, la Acrópolis.

Esta enorme y excepcional construcción ha sido una abundante fuente de datos acerca del reino de Talol, todo ello gracias a que un gobernante muy especial tuvo la visión y el deseo de trascender más allá de su vida y su muerte, posiblemente sin tener idea del alcance que tendrían sus obras y del tiempo que tardarían en ver la luz de nuevo, o más bien pensando que siempre estarían a la luz.

Ukit Kan Lek Tok' decidió dejar su huella materialmente en todo su palacio: pisos, paredes, bóvedas, banquetas y en gran cantidad de materiales. Y aun después del fin de su gobierno, sus sucesores se encargaron de continuar su legado queriendo perpetuarlo, pues lo siguieron nombrando muchos años después de muerto, también como una manera de legitimar su linaje real. Enorme fue la influencia que ejerció en su reino y en sus habitantes.

El hallazgo acelerado y continuo de textos nos mantuvo muy ocupados y sobre todo al Dr. Lacadena, que estaba sorprendido y fascinado con lo que estábamos obteniendo en un solo edificio y lo que eso significaba. En pocos años era tan amplio el acervo obtenido, que en su publicación de FAMSI (2003) el Dr. Lacadena mencionó que el corpus glífico de Ek' Balam era «... uno de los más extensos que se conocen del Norte de Yucatán por el número de textos y el número de bloques glíficos conservados, equiparable en importancia a los de Edzná, Xcalumkin, Oxkintok, Chichén Itzá y Cobá». 
Y aun después de esta aseveración, el corpus siguió aumentando, aunque no al mismo ritmo que antes, debido a que los recursos para la investigación no siguieron fluyendo de igual manera, llegando a cortarse casi por completo y causándonos una gran frustración, tanto a él como a nosotros, a sabiendas de lo que aún permanece oculto entre los escombros de las áreas derrumbadas del palacio real; la parte sin explorar en la Acrópolis puede contener una gran cantidad de información, quizá equiparable o mayor a la que ya se ha recuperado en la primera parte. El Dr. Lacadena, al igual que nosotros, siempre conservó la ilusión de continuar conociendo los textos de Ek' Balam e hicimos muchos planes de trabajo, que tristemente se vieron truncados a principios de 2018 con su irreparable pérdida.

Recordamos que, una vez iniciado el trabajo con los primeros textos, nos dimos cuenta del tesoro que teníamos en las manos y este sentimiento se reforzó en el momento en que liberamos las Serpientes Jeroglíficas, ya que pudimos ver el glifo emblema, pues aunque no teníamos la capacidad de leerlo, entendimos las implicaciones de su presencia. Ya el Dr. William Ringle (Ringle y Bey 1995) había reportado la existencia de un Glifo Emblema en la Estela 1 de Ek' Balam, destacando las implicaciones políticas de este hecho, pero el glifo no se pudo interpretar entonces debido a la fuerte erosión del monumento.

En 1997, cuando liberamos la fachada sur del Primer Nivel de la Acrópolis, las esculturas con el Glifo Emblema quedaron a la vista de todos, y no faltó quien quisiera publicar este descubrimiento antes de que lo diéramos a conocer nosotros; pero al enterarse el Dr. Lacadena, se comunicó con ellos y les dijo que presentaríamos nuestro trabajo en el VIII Encuentro de Investigadores de la Cultura Maya, en la Universidad de Campeche, en Campeche, México, en el año 1998 y la publicación salió en 1999 (Vargas et al. 1999). Caballero como solía ser el Dr. Lacadena, se les menciona en nuestro artículo como quienes llegaron «independientemente a conclusiones similares» respecto al glifo emblema y les entregó nuestro artículo, que ellos tuvieron que citar.

Para él no era problema compartir su información y siempre mantuvo el contacto profesional y la amistad con otros epigrafistas y con muchos otros investigadores, con quienes intercambiaba información y se nutrían recíprocamente de sus amplios conocimientos y nuevos descubrimientos.

El Glifo Emblema hermosamente labrado en cada una de Las Serpientes Jeroglíficas y luego su aparición en varios otros textos, permitieron al Dr. Lacadena contar con más información para sugerir una transcripción del Glifo Emblema como Talol, cuyo significado desafortunadamente permanece desconocido hasta hoy y ese es uno de varios datos en los que siempre continuó trabajando para poderlo aclarar o precisar.

Estos primeros años de intenso trabajo dieron como fruto la magnífica obra del Dr. Lacadena García-Gallo, publicada en línea por FAMSI, en el 2003, El Corpus Glifico de Ek' Balam, Yucatán, México. Research Report Submitted to the Foundation for the Advancement of Mesoamerican Studies, donde escribiría entre los agradecimientos: «Nada de lo aquí presentado hubiera sido posible sin la fructífera colaboración y la amistad durante los últimos años con la Arq. Leticia Vargas de la Peña, directora del Proyecto Ek' Balam, y el Arq. Víctor Castillo Borges, arqueólogo y jefe de campo del proyecto. Las conversaciones mantenidas con ellos durante varios años, su ejemplar disposición al trabajo interdisciplinar y su generosidad me han permitido poder estudiar este material en un excelente ambiente de estímulo académico y satisfacción personal» (Lacadena 2003: 121). 
En esa obra analizaba el material recuperado en Ek' Balam hasta entonces, un total de veintisiete textos jeroglíficos: la Estela 1, la Columna 1, la Serpiente Jeroglífica Oeste y la Este; doce tapas de bóveda (TB) 1, 2, 3, 4, 6, 7, 9, 10, 14, 15, 18 y 19 que eran las que tenían textos glíficos, entre el total de tapas pintadas; cinco murales jeroglíficos contenidos en el llamado Mural de los 96 Glifos, del Cuarto 29 Sub; el Mural del Cuarto 22, y siete textos misceláneos, TM1, TM2, TM3, TM4, TM5, TM6 y TM7.

Se incluyeron los textos conocidos más importantes del sitio, que permitieron esbozar la historia dinástica de Ek' Balam durante los cien años de tiempo que cubren, desde el último tercio del siglo VIII d.C. hasta mediados del siglo IX d.C. La dinastía reinante en Ek' Balam, durante el Clásico Tardío, fue iniciada por Ukit Kan Lek Tok' y continuada por K'an B'ohb' Tok, Ukit Jol Ahkul y ... K'uh....nal (probablemente Kihnich Jun Pik Tok Kuhnal) (Lacadena 2003) además de la posible inclusión de Kahkal Chu', al final de la lista antes mencionada (Vargas et al. 2007).

Aunque el Dr. Lacadena presentó la mayor parte de los resultados de su estudio en la publicación de FAMSI, y en conjunto publicamos otros datos, nos faltó mucho por hacer; su trabajo se vio truncado por el destino y nuestros muchos planes de trabajo conjunto y el mayor proyecto, que era publicar un libro sobre Ek' Balam y principalmente sobre Ukit Kan Lek Tok' y su dinastía; ahora tendremos que concluirlo sin él y lo haremos en su honor.

Como hemos mencionado, este trabajo no está planteado para dar a conocer datos nuevos sobre Ek' Balam, solamente queremos homenajear al investigador, al amigo y su proceso de trabajo con los textos de Ek' Balam, en su camino hacia el descubrimiento de la rica historia de este peculiar sitio arqueológico. Queremos compartir breves fragmentos de algunos de los mensajes que el Dr. Lacadena nos envió, mismos que habíamos guardado en una carpeta olvidada y descubrimos recientemente; ahora nos arrepentimos de no haberlos preservado todos. Los compartimos así, originales, con algunos errores «de dedo», con algunos comentarios personales, pero eso queremos precisamente, pues muestran su arduo trabajo y a la vez, reflejan la manera de ser de nuestro apreciado amigo, tan bromista y a veces hasta un poco niño.

En 1999, aunque parezca mentira, los autores no teníamos correo electrónico, simplemente era algo que no habíamos necesitado; ahora que dependemos de los medios electrónicos para todo, esto suena un poco extraño. Pero en esa época tampoco teníamos cámaras digitales, tomábamos fotografías y teníamos que llevar los rollos a revelar e imprimir. La verdad es que eso nos complicó un poco las cosas cuando Alfonso estaba en España y nosotros en Mérida y peor aun cuando estábamos en Ek' Balam, pues teníamos que esperar hasta llegar a Mérida los fines de semana para imprimir las fotos, que muchas veces se terminaban hasta la siguiente semana. Ahora es difícil pensar en cómo eran las cosas hace años, no tan fáciles como en la actualidad. Al principio nuestra comunicación fue por medio de una amiga común, quien sí tenía correo electrónico y gracias a ella estuvimos en contacto muchas veces.

Afortunadamente, hubo épocas en que felizmente el Dr. Lacadena podía estar en Mérida, gracias a los cursos que impartió en la Facultad de Antropología de la Universidad Autónoma de Yucatán y podíamos trabajar conjuntamente; pero principalmente la beca de FAMSI le permitió dedicar un buen tiempo al análisis de los textos de Ek' Balam, dando como fruto el magnífico trabajo ya mencionado.

En 1999, afortunadamente estábamos comunicados gracias al correo de una amiga (Figura 1): 
Date: Thu, 22 Apr 1999 14:49:01+0200

From: Alfonso Lacadena 〈alfonsođshapshu.filol_csic.es〉

To: zaguirreatunku .uady.mx

Subject: Carta para Leticia y Roch

[The following text is in the "iso-8859-1" character" set]

[Your display is set for the "US-AScII" character set]

[Some characters may be displayed incorrectly]

Queridos Leticia y Roch:

Fue estupendo recibir noticias vuestras. He ido sabiendo por cartas de Pilar y Lilí que todo os ha ido muy bien y que los trabajos en Ek' Balam son de quitar el aliento. Todo el mundo en Epigrafía está alucinado con el sitio, y muy interesado en 10 que vais encontrando. Si chich'en era importante para la historia de Yucatán, ahora hay que incluir Ek" Balam no sólo para entender la región sino también para entender el propio chich"en. Estoy deseando ver 105 avances en Ek" Balam y volver a comer esos huevos. motuleños en el restaurante del cenote de Valladolid.

Dentro de menos de dos semanas nos veremos (¿queréis algún encargo especial de España? dos apetece algo especial? dalgo de mi tierra, de las tiendas libres de impuestos del aeropuerto? Mo tengáis pena en pedirlo). Hay que ver, qué rápido han pasado estos cuatro meses desde que me vine. Hay cosas del equipaje que traje que no me ha dado tiempo a sacar de las bolsas y ordenar, así que me lo llevaré otra uez de vuelta a Mérida. He parece que acabo de llegar a España. A mi esposa, Laura, también, le parece que acabo de llegar y ya me voy, sobre todo ahora que está embarazada.

LLegó muy bien el fax con el dibujo del texto. QUE Marauilla. Roch ha hecho un dibujo muy bueno, y se ve que puede valer así como está. Debe sér una preciosidad la pieza original.

Una pregunta que haría es si en el último bloque, C3, el signo que hay a 1a izquierda del numeral 4 es realmente un signo o es un motivo que forma arte de 1 a representación iconográfica del tocado de $K$ 'awil. En 105 bloques c2-c3 está el nombre de nuestro hombre, Ukit Kan Le:k. Este nombre está siempre escrito de manera muy reqular en las otras inscripciones, como u-ki-ti 4-1e-ku (fijaos, por ejemplo, en la Tapa de Bóveda 3 o en las Serpientes Jeroglificas), y por tanto 10 que hay a la izquierda del 4 no haría mucho sentido, a no ser que fuera en realidad parte de la iconografía, posiblemente pegada al texto por esa parte. Lo que parece es que se dibujó primero la iconografía, ya que inuadió el espacio pensado para el texto escrito. Imagino que cuando el escriba fue a escribir el último bloque se encontró sin sitio suficiente, y lo empequeñeció. Creo que es por eso por lo que los puntos del número cuatro son tan pequeños. realmente más rayas que puntos. Habría que checarlo. En el análisis he considerado que forma parte de la iconografía.

0s escribo un comentario preliminar al texto de la Tapa (creo que es la 6 ):

TAPA DE BOUEDA 6 DE EK' BALAM

El texto consta de 9 bloques glíficos, y se lee en el orden A1, A2, A3, A4, $\mathrm{A} 5, \mathrm{~B}, \mathrm{C} 1, \mathrm{C} 2$ y $\mathrm{CB}$.

(A1) II-MEN

(A2) K'IN-ni

(A3) tU-UIII-TE*

Figura 1. Correspondencia a través del correo-e de una amiga común de la Universidad Autónoma de Yucatán (1999).

Para entonces, no había definido completamente cómo escribir el nombre de Ukit Kan Lek Tok'. Se usaba entonces todavía el fax, por medio del cual le mandábamos los dibujos y él nos escribía por correo electrónico sus comentarios sobre los textos. Ahora parece irreal, pero empezamos a tramitar el servicio de internet y por distintas 
razones no lo tuvimos pronto, y cuando lo tuvimos, fallaba mucho, pero los buenos amigos nos apoyaron posibilitando la comunicación. Ahora lo recordamos riendo, y pensando que parecíamos vivir en el siglo antepasado.

Después de otros comentarios sobre los textos (para ese entonces recientemente hallados) él siempre terminaba con sus bromas (Figura 2):

\begin{abstract}
precediendo el numeral del mes. Este rasgo, así como otros paleográficos presentes en el texto -como es la escritura del signo ja en el bloque (B) cuando en realidad está en secuencia con ma-ka del bloque (A5), formando la expresión ma[h]kaj 'fue cerrado/cubierto'--, insertan perfectamente la escritura de Ek' Balam en el contexto epigráfico regional.

El personaje mencionado en el texto es el rey Ukit Kan Le:k, el mismo que ya aparece mencionado en otros textos de Ek Balam, como la Estela 1, las Serpientes Jeroglíficas o la Tapa de Bóveda 3 (estos últimos textos se encuentran asociados a la gran Estructura 1 o Acrópolis, 10 que señala al gobernante Ukit Kan Le:k como uno de los principales responsables de la fisonomía final de la estructura). El texto le identifica como el poseedor del cuarto en el que apareció la Tapa de Bóveda, y cuya terminación está conmemorando el mismo.
\end{abstract}

Espero que os sirua 10 que mando, no sé si necesitáis algo más.

(léanse ahora estas preguntas que siguen como pronunciadas por un perrito con la lengua fuera, babeando -como Dino de Lilí-, dando saltos alrededor vuestro) ¿Dónde ha aparecido la Tapa de Bóveda? ¿Tanbién en la Estructura 1? ¿Arriba en alguna de las plazas? ¿En cuartos laterales al ras de la plaza principal como la TB 3 ? ¿Hay fechas en las otras tapas de bóveda o los nombres de los propietarios? ¿Hay textos en piedra? ¿qué fue del misterioso pasillo que penetraba hacia el interior de la ecrópolis? „11ego a tiempo? ay, no sé si podré esperar a ver los textos.

Realmente, viendo todo lo que estáis sacando, ahora no tenqo ninquna duda de que finalmente Roch encontrará su códice en una caja sellada de piedra y que Leticia tendrá una calle a su nombre en Ualladolid. El primer desayuno de reencuentro (parecemos ejecutivos con eso de desayunos de trabajo) 10 pago yo, para celebrar.

Escribidme para 10 que necesitéis.

Un abrazo muy fuerte,

Alfonso

Dr. Alfonso Lacadena García-Gallo

Laboratorio de Hermeneumática

Instituto de Filología

Consejo Superior de Investigaciones científicas

c) Duque de Medinaceli 8

28014 Madrid

Te1. 914296626 Ext.2615.

Fax. 913164196

Figura 2. Parte final de un correo-e de Alfonso en su línea bromista habitual. 
Aquí algunos fragmentos de los comentarios del Dr. Lacadena sobre el hallazgo de la tumba; el mensaje debió de ser más o menos de fines de 1999 (Figura 3):

Querida Leticia y Víctor,

¿qué tal estáis? Imagino que bien, contentos, aunque, como siempre, estresados y liados con tanto nuevo descubrimiento. Es increíble todo lo que estáis recuperando del sitio de Ek' Balam. Habéis hecho de Ek' Balam uno de los sitios estrella de Yucatán. En el último artículo de Stephen Houston, que trata sobre la epigrafía en los últimos diez años, menciona a EK Balan como uno de los sitios más prometedores en ei hallazgo de nuevos textos (menciona en bibliografía nuestra ponencia de Campeche). Las noticias y fotos que me mandáis con las nuevas tapas de bóveda son increíbles.

Como las noticias vuelan, ha llegado hasta España la noticia del hallazgo de la tumba - fue una conocida común, Lupita Cámara. Ay, qué nervios. Me dijo que hay glifos, aunque no me contó bien dónde o cuántos. Ojalá se pueda identificar al ocupante, y ojalá sea nuestro querido 'Ukit Kan Le'k u otro de los reyes de Ek' Balam. Creo que nunca podría superar encontrarme a ese increíble monarca como cautivo en Cobá o en otro sitio. Nuestro rey, el gran remodelador de la Acrópolis, la gloria de Yucatán, se merece haber tenido un final sereno y una tumba digna.

Iré a Yucatán a comienzos de Mayo, y me quedaré hasta mediados de Julio, a dar las clases en la Facultad. Yo creo que un último vistazo a los textos nuevos del sitio para checar las dudas, y ya estará todo preparado para los dibujos finales y los comentarios. El ofrecimiento de publicar un especial sobre Ek' Balam en Arqueología Mexicana me parece excelente, y no deberíais desaprovechar la oportunidad. Es una ocasión muy buena de divulgar los últimos hallazgos, y sirve de reconocimiento a todo el trabajazo que habéis hecho allí.

Unos comentarios sobre los textos y glifos del sitio:

- Sobre el nombre del reino de Ek' Balam: como sabéis, el Glifo Emblema de Ek' Balam se compone de un signo TAL y otro lo, TAL-lo. Durante los últimos seis meses hemos avanzado mucho en el conocimiento de las reglas de complementación fonética y la

Figura 3 (esta página y la siguiente). Carta en la que comenta la llegada a España de noticias sobre una tumba con glifos y el posible nombre de Ek' Balam, Talol (2000). 
(Figura 3. Continuación)

disarmonía vocálica (trabajos de Stephen Houston, David Stuart, John Robertson, Soeren

Wichmann y míos), y podemos considerar lo siguiente:

- Hay muchas posibilidades de que el reino de Ek' Balam se llamara Talol en el periodo Clásico: TAL-lo, Tal[o]l.

- En Ikil no se menciona el reino de Ek' Balam, sino otro sitio, ma-TAL-lo, Matal[o]l. Matalol, aparece en uno de los jades de Chichén Itzá, probablemente abreviado, como ma-TAL.

- El nombre completo del rey es 'Ukit Kan Le 'k Tok', normalmente mencionado como 'Ukit Kan Le' $k$. Como ya dijimos en la ponencia de Campeche, en la Serpiente Jeroglífica Oeste aparecía el nombre de este gobernante en lo que tenía que ser su forma completa, escrito como 'u-ki-ti KAN-le-ku to-\# (además de los títulos de Kalomte' y K'uhul 'Ajaw, "sagrado rey"), siendo \# una variante de cabeza con forma de calavera y marcas de pedernal. El lexema Tok' queda ya claro por la Tapa de Bóveda 15, donde aparece escrita también una versión extensa del nombre del rey, pero donde lo que correspondería a to-\# es la forma normal del logograma TOK, "pedernal". Gracias al ejemplo de la Tapa de Bóveda 15, se puede ver que to-\# y TOK' se sustituyen sintácticamente, por lo que ambos tienen que decir lo mismo. Por tanto, en la secuencia de signos to-\# de la Serpiente Jeroglífica Oeste, to es un complemento fonético y \# no es más que la variante cefalomorfa de TOK' "pedernal", es decir, to-TOK'. De hecho, ahora se pueden entender unas formas aberrantes del logograma "pedernal" de Chichén Itzá —en el compuesto idéntico toTOK' - como variantes gráficas del signo cefalomorfo que aparece en Ek' Balam.

- La Tapa de Bóveda 10 es una maravilla por la calidad del dibujo, fino, seguro y delicado como los mejores ejemplos de cerámico tipo códice. En el texto hay una fecha que se conserva bastante bien y que puede reconstruirse. En las fotos que me mandasteis puedo distinguir lo siguiente:
(A1) 5-IMIX-ni
(A2) ??-'OL-la
(A3) ma-ka-ja
(A4) 'u-WAY-li

A diferencia de otros investigadores que lo interpretaron de otra manera, él, desde un principio, estuvo seguro de que el nombre del reino era Talol, aunque entonces no quisiera afirmarlo rotundamente y su profesionalismo le exigía cerciorarse de sus resultados.

Acerca del monumento de piedra labrada, nombrado Columna 1 (Figura 4), supimos que los fragmentos hallados formaban una sola pieza, pero él lo confirmó con la lectura de los textos, como explica aquí (Figura 5): 


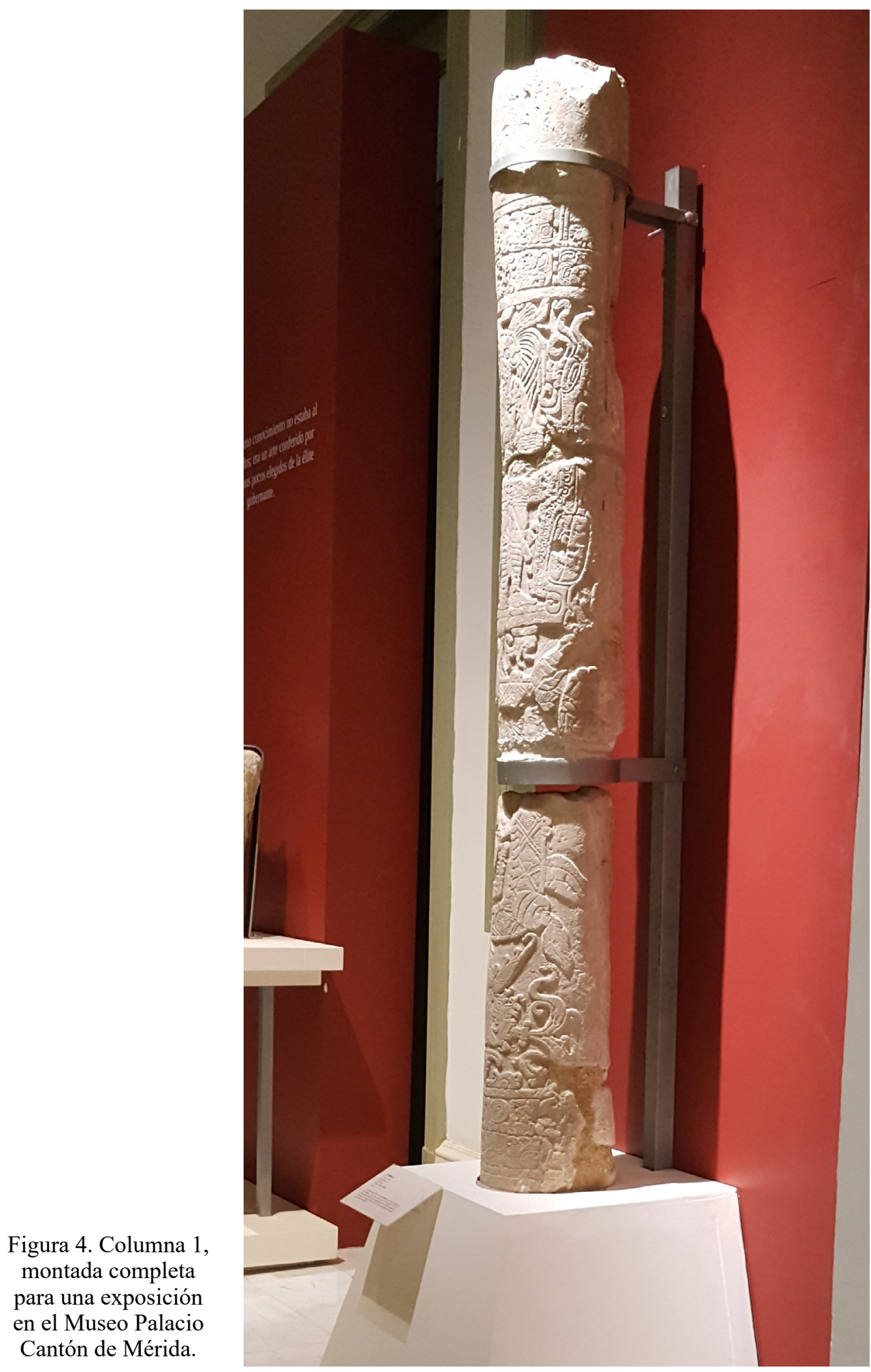



(A5) 'u-k'a-[li]
(A6) WAL-la-??-TUN-ni
(B1) 5-'AJAW-wa
(C1) \#\#
(D1) \#-\#-\#-\#-la
(E1) ['u]-\#-ti-\#\#
(F1) \#\#

El día es claramente 5 Imix (bloque A1); el mes es Kumk'u (escrito en Cholano, en A2, como 'OL-la); el numeral del mes está escrito con una variante de cabeza que no puedo ver bien en las fotos, pero que tiene que ser la correspondiente a 4, 9, 14 o 19; el tun (bloque A6) lleva un numeral que podría ser 2 , aunque podría haber un espacio para 7,0 - mucho menos probable - 12; la referencia al K' atun (bloque B1) es clara, 5 'Ajaw. Con esta información, las únicas alternativas posibles son:

10.0.1.15.1 5 Imix 14 Kumk'u, 2 Tun 5 'Ajaw, 5 de enero de 832 d.C.

10.0.6.16.1 5 Imix 9 Kumk'u, 7 Tun 5 'Ajaw, 29 de diciembre de 836

10.0.11.17.1 5 Imix 4 Kumk'u, 12 Tun 5 'Ajaw, 23 de diciembre de 841

Si se confirma que el numeral del tun es 2 , la primera fecha sería la correcta (tengo que checarlo).

La sintaxis del texto es muy interesante, ya que divide la fecha en dos partes, introduciendo entre la Rueda Calendárica y la notación del tun-k'atun la expresión verbal: ma-ka-ja 'u-WAY-li 'u-k'a-[li], ma[h]kaj' 'uway[i]l 'uk'aal, "fue cerrado el aposento, el cuarto de"; el nombre del propietario está en los bloques C1-E1, pero no lo leo bien en las fotos. En el bloque E1 leo la secuencia ['u]-\#-ti, que podría corresponder a 'Ukit, pero no distingo bien lo que precede a esta secuencia y lo que le sigue. Aunque después de ['u]-\#-ti no hay un número cuatro, necesario para KAN, de 'Ukit Kan Le 'k, no debe ser descartado, ya que puede haber sido escrito con la variante de cabeza, como en la Tapa de Bóveda 7.

- La Columna es una sola pieza. La inscripción es una sola: la banda horizontal de arriba con la Serie Inicial se continúa en la banda horizontal de abajo, y la escena iconográfica casa perfectamente en los fragmentos de la misma. La fecha es 10.0.0.0.0 7 'Ajaw 18 Sip, y se corresponde al 15 de marzo 830 d.C. Menciona a 'Ukit kan Le'k y a otro personaje cuyo nombre también comienza con 'Ukit. Ambos llevan el título de rey de Talol.

\section{Y la despedida, siempre con bromas (Figura 6):}

Bueno, amigos míos, espero que nos veamos pronto, que todo siga como hasta ahora (y que Roch encuentre el códice). Me muero de impaciencia por platicaros de todo esto, ver las maravillas del sitio, los glifos de la tumba y por comer en Valladolid Huevos Motuleños, como siempre.

Saludadme a Liz, Ambar y Yazmín.

Un abrazo muy fuerte,

\section{Alfonso}

PD. Para lo que queráis, ya sabéis que mi teléfono de acá es 91-6346417, FAX 91-
Figura 5. Un breve comentario sobre la Columna 1 , su colocación y lectura (2000).
Figura 6. Parte final, jocosa, de la carta de las Figuras 3 y 5 (2000). 
En respuesta a su deseo de saber de la tumba (entonces recién hallada), le escribimos un largo mensaje, para que se lo enviara nuestra amiga mutua, porque sabíamos que quería conocer todos los detalles y que se lamentaba de no haber estado en Ek' Balam para disfrutar junto con nosotros esa ocasión única en la vida (Figura 7):

Mérida, Yucatán, 7 de marzo de 2000.

Querido Alfonso:

Primero que nada gracias por la carta y por la pulserita, está preciosa. Nos dio mucho gusto volver a ver a Pilar, y además que trajera noticias tuyas.

El asunto de Internet ha sido un desastre, porque cuando al fin me he decidido a inscribirme - principalmente para que podamos comunicarnos contigo y contarte los últimos acontecimientos - no ha querido funcionar, primero el modem y luego el servicio de Telmex, así que lo voy a tener que cambiar, pero casi no estamos en Mérida y eso lo dificulta más. Total que seguimos en la prehistoria, porque actualmente eso es el no tener Internet. Pero Pilar nos va a hacer el favor de enviarte este mensaje.

No sabes como desearíamos que ya estuvieras aquí, han sucedido las cosas más increíbles y cada vez que hallamos alguna inscripción, lo primero que decimos es ¡Alfonso va a morir cuando vea esto! Como ya te enteraste, encontramos la primera tumba real de Ek' Balam, pero lo que no sabes es que se trata de nuestro hombre, Ukit Kan Le'k Tok (óigase el sonido de las fanfarrias) sí, aunque usted no lo crea. Casi sin pensarlo llegamos a él, estábamos haciendo un pozo estratigráfico - por encima de las fachadas teratomorfas- en el que ya llevábamos aproximadamente un mes, cuando llegamos a la bóveda, que es la del cuarto posterior a la fachada principal y dentro de ella hallamos otra pequeña bóveda que resultó la cámara mortuoria. Una parte de ella se había desplomado y dañó un poco las piezas, que estaban rotas, pero completas; así que desde el día martes 11 de enero, de este tan esperado año 2000, nos sumergimos en las profundidades de la tumba.

Pero no te hemos dicho lo más chistoso: no sabíamos de quien se trataba y no lo supimos hasta días después de sacarlo, pero esto va después.

Nos pasamos diez días, del amanecer al anochecer, incluso sábado y domingo, sacando las cantidades enormes de materiales que formaban parte de la ofrenda, nos dio trabajo debido al desplome de la bóveda, por el cual estaba fragmentadas las vasijas y un poco revuelto todo con tierra y escombro, pero pudimos poner a salvo todas las piezas y bastante bien. Todos esos días, a pesar de ser tan agotadores, fueron maravillosos, pero creo que el mejor momento fue el sábado por la mañana, cuando Roch vió en uno de los fragmentos de una vasija, el glifo emblema. En ese momento confirmamos que se trataba de un rey, y creo que en el fondo quizá presentíamos que era Ukit, pero aun no lo sabíamos.

No lo vas a creer, pero había más de 5000 pequeños caracoles perforados; cientos de placas de concha; pendientes de jade, concha y hueso; unos aros grandes de concha nacarada y de jade, unos pendientes en forma de camarones (ifantásticos!) otro en forma de venado (muy parecido al del mural) y montones de piezas más, preciosas. Pero unas de las más sobresalientes son unas pequeñas calaveras de concha con mandíbulas movibles, sencillamente increíbles. Un cuchillo enorme, de obsidiana y otros de pedernal y muchas cosas más.

Figura 7. Carta de los autores a Alfonso con las excelentes novedades de la Tumba de Ukit Kan Lek Tok' hallada dos meses antes (7 de marzo del 2000). 
Esta carta continúa en la siguiente imagen (Figura 8):

Hay 21 vasijas, cuatro de ellas de alabastro y una de barro maravillosamente decorada con dos escenas, en las que intervienen dos personajes - los mismos en cada una- y con una inscripción casi perfecta. Esta vasija la restauraron y en ese momento pudimos Roch y Yo ver que, al fin, teníamos a nuestro hombre; ahí estaba Ukit Kan Le'k (ahora Tok). Ese día escribí en mi bitácora: "Perdónanos gran Ajaw, por perturbar tu sueño eterno, pero el mundo tiene que conocer tu grandeza".

Pero esto no es todo, además parece estar su nombre en un hermosísimo cetro de hueso, que tiene una inscripción fabulosa. Pero ya no te digo más, porque pronto lo verás todo.

Y después de esto, que nos hizo sentir que ya no teníamos nada más que pedir y que nada nos sorprendería tanto juna nueva sorpresa de la antigua Talol! En otro pozo, hallamos una subestructura, y dentro de ella -el jueves 10 de febrero de 2000 - inició su aparición un hermoso mural de color rojo, negro y azul ¡lleno de glifos! o más bien tenemos que decir que son puros glifos y está casi perfecto, así que, querido amigo, Roch no ha encontrado el códice (aun) pero si una página de él y aquí está, esperando que la leas.

Es un panel de $2.93 \mathrm{~m}$. de largo y aproximadamente $50 \mathrm{~cm}$. de ancho, enmarcado con una banda roja y debajo, fuera del panel, hay otros glifos, unos muy grandes, otros medianos y unos más pequeños, que no están terminados, son solamente los trazos con líneas negras y el espacio demarcado para otros que nunca fueron dibujados; mientras que los que están enmarcados fueron delineados con negro y pintados completamente de rojo unos, y de rojo y azul otros, al parecer los numerales. Hay más de 160 glifos, no recordamos ahora el número exacto; las dos filas de en medio parecen ser sólo numerales y vemos al menos dos glifos emblema más, aparte del de Ek' Balam

Ya te habíamos hablado del catálogo de pintura mural que estamos haciendo con la UNAM y queríamos preguntarte si citamos la información que nos has enviado por carta como: "comunicación personal" o Tú dinos como te parece más correcto. Igualmente si pudieras leer algo del panel jeroglífico, lo incluiríamos en el catálogo, pero solamente tenemos hasta fines de abril para entregarlo, así que será un poco difícil.

Pilar nos dijo ayer que se va a España un amigo de ella y te íbamos a enviar las fotos del mural, pero Mérida está en medio del Carnaval y no abrió Omega, asi que no pudimos recogerlas; pronto trataremos de mandarlas, aunque sea por mensajería.

Bueno, moriremos de impaciencia mientras vienes, pero nos consuela saber que ya es poco tiempo y te esperaremos comiendo unos deliciosos huevos motuleños a tu salud.

Seguiremos en contacto y mientras tanto, te mandamos un abrazote.

Leticia y Roch

Figura 8. Continuación de la carta con la novedades de la Tumba de Ukit Kan Le'k Tok, incluyendo el Mural de los 96 Glifos en una subestructura (7 de marzo del 2000).

La emoción del hallazgo de la tumba y poco después del mural que él bautizara como el Mural de los 96 Glifos (Figura 9), es indescriptible y sabíamos que nuestra alegría era compartida por Alfonso desde lejos, lo que nos hacía disfrutar doblemente, al contarle y a sabiendas de la euforia que sentiría al llegar a Ek' Balam y ver todo el material. Tuvimos que mandarle por mensajería las fotos del mural, para que lo conociera y pudiera empezar su análisis y por supuesto, porque nosotros estábamos impacientes por saber qué maravillas nos contaría. Este mensaje es de cuando recibió las fotos (Figura 10): 


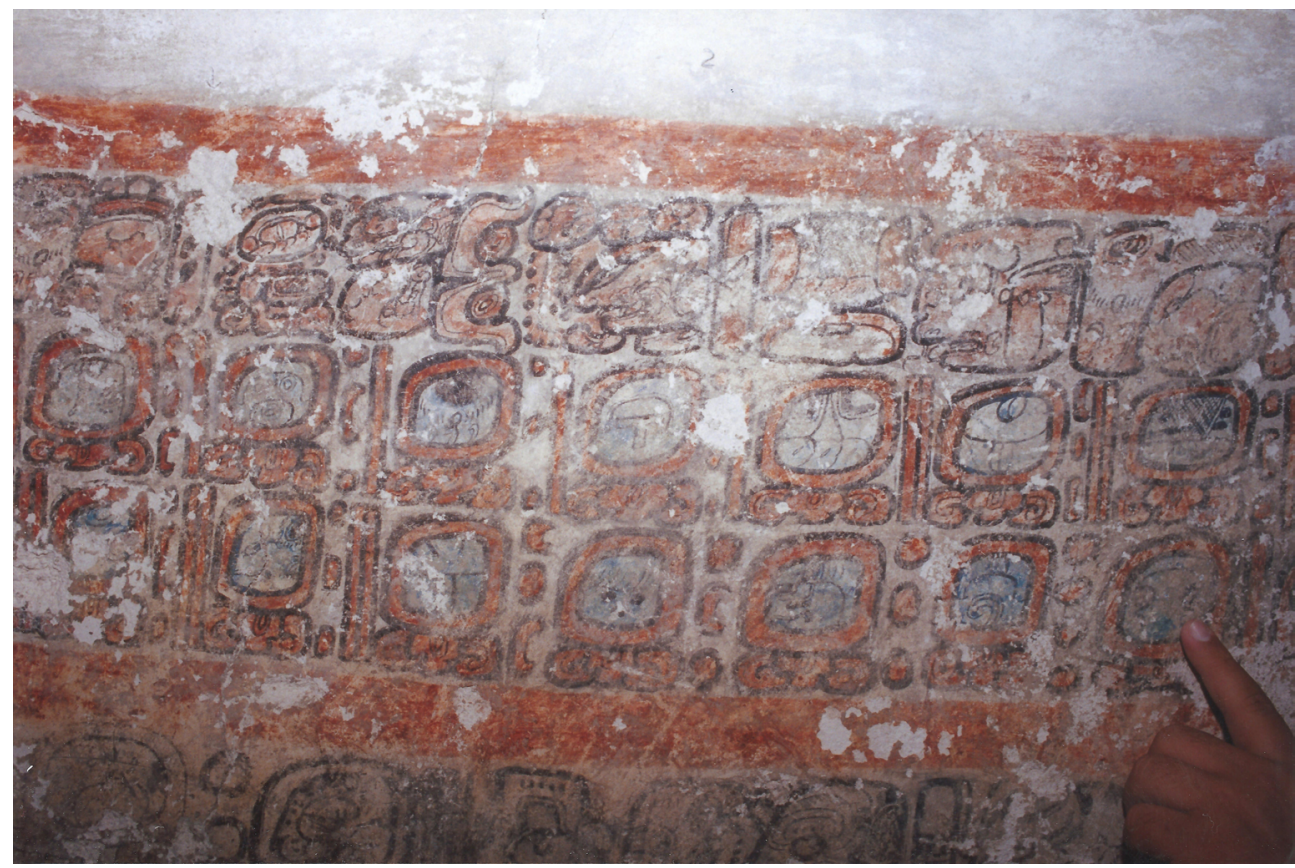

Figura 9. Fragmento del Mural de los 96 Glifos. Una de las primeras, entre la amplia serie de fotos que Alfonso recibió y sobre las que trabajó inicialmente.

De: Laboratorio de Hermeneumatica <alfonso@shapshu.filol.csic.es>

Para: pzabala@finred.com.mx <pzabala@finred.com.mx>

Fecha: lunes 3 de abril de 2000 13:25

Asunto: Carta para Leticia

Madrid, 30 de marzo de 2000

Queridos Leticia y Roch:

Anteayer por la noche, al llegar a casa, encontré por fin que llegó

el envío de mensajería con las fotos del mural de la subestructura que me enviasteis. No tengo palabras, es alucinante. Llevo dos días con subida de adrenalina, el corazón disparado y una absoluta imposibilidad de concentrarme y pensar y hacer otra cosa que no sea la contemplación de semejante maravilla. Es tan grande mi excitación, que estoy haciendo un esfuerzo enorme ahora para hilar frases coherentes, volver a este mundo y decir algo más sobre el Mural que la salmodia

'es-alucinante-es-alucinante-es-alucinante-es alucinante'. Y es que es increíble lo que habéis encontrado. Tengo mil comentarios que hacer --el mural se presta para un montón de cuestiones--, pero creo que lo mejor será que os envie ya unos comentarios rápidos, aunque sean preliminares.

El Mural consiste en realidad en cuatro murales distintos, realizados en cuatro momentos diferentes. Para aclararnos, voy a llamarlos ahora Texto 1, Texto 2, Texto 3 y Texto 4.

Figura 10. Contestación a la llegada de las fotos del Mural de los 96 Glifos (3 de abril del 2000). Fragmento. 
Después de los comentarios, que según él eran «rápidos y preliminares», sobre los textos del mural, aunque sí los hizo sorprendentemente pronto dada su complejidad, termina la larga carta anterior con estos comentarios (Figura 11):

De: alfonso@shapshu.filol.csic.es<alfonso@shapshu.filol.csic.es>

Para:Pzabala@pibil.finred.com.mx<Pzabala@pibil.finred.com.mx>

Fecha: lunes 3 de abril de 2000 13:26

Asunto: Carta para Leticia

$\ll<$ This message is part 2 of a previous message $\gg>$

una ofrenda de dedicación; en este sentido, tut es sinónimo de mak 'cerrar, cubrir', que es el verbo más usual, como en la tapas de bóveda de Ek' Balam, con su ma-ka-ja, ma[h]kaj 'fue cerrado/cubierto'). Por su parte, tak', como señaló Stephen Houston en los ejemplos del Códice de Madrid, es 'pegar, estucar, emplastar'. Si bien existen otras acepciones (sobre todo para tak'), podrían ser verbos que se refieren a los actos de dedicación de la estructura (tut) y -sería interesante- al estucado o pegado (tak') del mural a la pared. En el Texto 3 hay otro verbo, muy claro, hu-li, huli 'llegó' o 'llegaron', y se refiere a la 'llegada' o visita de los personajes mencionados a este mismo recinto, cuarenta y cuatro después de su dedicación, posiblemete para realizar rituales en relación con el acontecimiento que conmemora el Texto 1 (¿un entierro? ¿la dedicación de un espacio sagrado, un santuario?).

Así pues, resumiendo, el proceso de realización del mural (o mejor, de los cuatro murales) sería el siguiente:

- Se pinta el primer mural, el Texto 1, haciendo mención a las fechas 9.19.11.16.12 y 9.19.12.1.1, separadas por 49 días.

- 36 años más tarde, se entra otra vez en el recinto y se realiza el Texto 2 , asociado a la fecha 10.1.8.4,0 (primer verbo, perdido).

- 8 años más tarde, en 10.1.16.5.14, se entra nuevamente en el recinto y se realiza el Texto 3. El texto explícitamente se refiere a esta nueva visita como hu-li, huli 'llegó/llegaron'. Uno de los personajes que llega al recinto es K'an Bob? Tok', que lleva el título de 'rey de Talol'; el otro personaje que le acompaña es Kan Ek' Bakab. Por la razón que fuera, el Texto 3 nunca se terminó

- Un visitante anónimo, iletrado, entra en el recinto y garabatea copiando algunos bloques glíficos de los textos ya escritos, uno del Texto 3 y dos del Texto 1, justo los que tiene encima.

Así que tenemos una verdadera maravilla, por su compleja e interesante realización. Tengo mil preguntas: ¿Cómo es arqueológicamente esa subestructura? ¿Es una cámara funeraria? ¿Hay restos de enterramientos u ofrendas? ¿Es un santuario? ¿Hay evidencias arqueológicas de que el recinto muestre episodios de sellado y reapertura? ¿Dónde está exactamente? ¿Qué material cerámico ha dado? ¿Qué conexión tiene con la tumba real y con los cuartos del edificio de la fachada teratomorfa? Sería excelente intentar correlacionar la historia arqueológica de la subestructura con la evidencia que presentan los textos del Mural (sería como el santuario del

Figura 11 (esta página y la siguiente). Parte final del correo-e, con todo tipo de preguntas sobre el contexto de los hallazgos (3 de abril del 2000). 
(Figura 11. Continuación)

resellado y reabierto en varias ocasiones, dejando constancia de las 'visitas' en varios medallones glíficos; el sellado y reapertura de recintos es práctica común en el Clásico Maya, como cuando las tumbas se abren para sacar los huesos y manipularlos ritualmente).

Esta información preliminar que mando --no tengo ni que decirlo--, por supuesto podéis emplearla como necesitéis para lo que tengáis que mandar para el catálogo de pintura mural. Podéis mencionarlo como 'comunicación personal' o, si se prefiere algo más formal, como 'según A Lacadena, epigrafista colaborador del Proyecto', o si preferís, podéis decirme qué extensión tendría el comentario epigráfico aproximadamente, y lo escribo y os lo envío rápidamente desde aquí, por correo electrónico vía Pilar, Lilí o Rach, destacando lo que creo que sería más importante para el catálogo (por ejemplo, no sería bueno mencionar todavía lo de

EK'-ba-ma-la/EK'-ba-la-ma hasta estar seguros, dadas las implicaciones que podría tener).

Cuidaos, amigos míos, y no os olvidéis de dejar por el sitio toneladas de cigarrillos (y algún que otro tamalito) para los aluxes. Iré pronto para allá. Idme pidiendo un Caribe-cooler bien frío (aunque Pilar y Lupita me insisten en que esa bebida es de señoritas).

Un abrazo muy fuerte,

Alfonso

Ardo en deseos de ver las otras piezas con inscripciones que aparecieron. Quizá podríais escanearlas y mandármelas como attachment en un correo electrónico.

Dr. Alfonso Lacadena García-Gallo

Laboratorio de Hermeneumática

Instituto de Filología

Consejo Superior de Investigaciones Científicas

C) Duque de Medinaceli 8

28014 Madrid

Tel. 914290626 Ext.2015

Fax. 913164196 
Esta carta es del mismo año, 2000, pero ¡al fin! ya teníamos correo electrónico, lo que facilitó enormemente la comunicación y el intercambio rápido de datos, que aún entonces nos seguía sorprendiendo (Figura 12):

\section{Leticia Vargas}

De: Laboratorio de Hermeneumatica <alfonso@shapshu.filol.csic.es>

Para: Leticia Vargas <ekbalam@sureste.com>

Enviado: Miércoles, 08 de Noviembre de 2000 07:51 a.m.

Asunto: Re: "Pilastra 1"

Querida Leticia,

acabo de recibir tu correo ahorita mismo, y te escribo de vuelta. Ahora mismo estamos los dos sentados ante la computadora. Me estremece siempre pensar en esta matravilla del correo electrónico, que tan bien conecta a la gente.

Gracias nuevamente por los datos, y por el permiso para presentar en marzo la ponencia sobre la dinastía de Ek' Balam. Creo que es muy bueno que la gente vea que el trabajo se va sacando pronto.

Necesitaría (casi se me olvidaba), el título de vuestra ponencia en

Campeche y el de la de Vera, para remitirme a ellas.

Aguardo el envío de las fotos y los dibujos.

Un beso muy fuerte,

Alfonso

Sobre la Pilastra, llevas razón. Yo la había llamado pilastra y no columna porque había estado adosada a un muro. pero es más correcto columna (aunque dudo que haya sujetado nada alguna vez). Así que Columna 1. Perfecto.

Dr. Alfonso Lacadena García-Gallo

Laboratorio de Hermeneumática

Instituto de Filología

Consejo Superior de Investigaciones Científicas

C) Duque de Medinaceli 8

28014 Madrid

Tel. 914290626 Ext.2015

Fax. 913164196

Figura 12. Primera misiva a través de correo-e directo a los autores (8 de noviembre del 2000). 
En los años que siguieron hubo tantos mensajes, que ahora lamentamos no haber guardado, pero estamos felices de tener los que aquí compartimos; nos sorprendió encontrarlos, pero los habíamos archivado por contener los primeros datos sobre algunos textos, pues nos servía de consulta, antes de que pudiéramos contar con su obra del 2003, la que, desde entonces ha sido de estudio imprescindible cada día. Además de usar la información como referencia, la revisamos frecuentemente por el mero disfrute de leer esos textos tan hermosos, al igual que lo hacemos con otras obras suyas o con nuestros trabajos conjuntos.

La satisfacción que sentimos al leer la información de los textos glíficos, se debe a que siempre nos ha asombrado la manera tan poética que tenían los mayas -en la época prehispánica- de contar su historia, de relatar sus eventos y creencias, los nombres tan bellos que tenían las personas, los extraordinarios títulos de sus gobernantes, su fascinante costumbre de ponerle nombres a los objetos inanimados y señalarse como sus poseedores. Alfonso pensaba igual que nosotros y muchas veces comentamos cuan exquisitos eran los textos glíficos de Ek' Balam.

Estamos muy agradecidos de haber podido disfrutar de tantos descubrimientos conjuntamente con el Dr. Alfonso Lacadena García-Gallo, fue un honor trabajar con él y lamentamos que esa época haya terminado, pero estamos contentos de haber sido testigos de su trabajo y le agradeceremos eternamente habernos brindado todo su tiempo y esfuerzo para alcanzar los resultados que nos han permitido ir leyendo la historia de Ek' Balam.

\section{Referencias}

Lacadena García-Gallo, Alfonso. 2003. El corpus glifico de Ek'Balam, Yucatán, México/ The Glyphic Corpus of Ek' Balam, Yucatan, Mexico. Foundation for the Advancement of Mesoamerican Studies, Inc. http://www.famsi.org/reports/01057es/01057esLacadenaGa rciaGallo01.pdf .

Ringle, William M. y George J. Bey. 1995. Proyecto Ek Balam. Preliminary Report on the 1994 Field Season. México: Reporte ubicado en el Archivo Técnico del Consejo de Arqueología del INAH.

Vargas de la Peña, Leticia y Víctor R. Castillo Borges. 2016. «Breve recuento de las investigaciones realizadas en Ek' Balam», en Arqueología del norte de la península de Yucatán: avances y exploraciones recientes, Lynneth S. Lowe y Tomás Pérez Suarez, eds., pp. 77-99. México: Centro de Estudios Mayas, Instituto de Investigaciones Filológicas, Universidad Nacional Autónoma de México.

- 2018. «El Doctor Alfonso Lacadena García-Gallo y Ek» Balam», en Tiempo detenido, un tiempo suficiente: ensayos y narraciones mesoamericanistas en homenaje a Alfonso Lacadena García-Gallo, Harri Kettunen, Verónica Amellali Vázquez López, Felix Kupprat, Cristina Vidal Lorenzo, Gaspar Muñoz Cosme y María Josefa Iglesias Ponce de León, eds., pp. 77-88. Couvin: Wayeb Publication Series, vol. 1.

Vargas de la Peña, Leticia, Víctor R. Castillo Borges y Alfonso Lacadena García-Gallo. 1999. «Textos Glíficos de Ek' Balam (Yucatán, México): Hallazgos de las Temporadas de 1996-1998», en Los Investigadores de la Cultura Maya 7-1, pp. 172-187. Campeche: Universidad Autónoma de Campeche.

Vargas de la Peña, Leticia, Víctor R. Castillo Borges, Alfonso Lacadena García-Gallo y Teresa N. Ceballos Gallareta. 2007. «El Cuarto 44 de la Acrópolis de Ek’ Balam», en Los 
Investigadores de la Cultura Maya 15-2, pp. 371-383. Campeche: Universidad Autónoma de Campeche. 